\title{
Experimental Adaptation of a Training Simulator for Manual Welding Processes towards the Teach-In of Welding Robots
}

\author{
Benjamin Knoke ${ }^{1 *}$, Mareike Voskuhl $^{2}$, Marcel Tebbe ${ }^{2}$, Markus Häveker $^{3}$, Christian \\ Gorldt $^{1}$, Klaus-Dieter Thoben ${ }^{1}$
}

\author{
${ }^{1}$ BIBA - Bremer Institut für Produktion und Logistik GmbH, University of Bremen, Hochschulring 20, \\ 28359 Bremen, Germany; *kno@biba.uni-bremen.de \\ ${ }^{2}$ University of Bremen, Bibliothekstraße 1, 28359 Bremen, Germany \\ ${ }^{3}$ Daimler AG, Mercedesstraße 1, 28309 Bremen
}

SNE 28(1), 2018, 27 - 30, DOI: 10.11128/sne.28.en.10404 Received: March 10, 2018 (Selected ASIM GMMS/STS 2018

Conf. Publ.), Accepted: March 15, 2018

SNE - Simulation Notes Europe, ARGESIM Publisher Vienna,

ISSN Print 2305-9974, Online 2306-0271, www.sne-journal.org

\begin{abstract}
This paper describes an attempt to provide assistance during the teach-in process of welding robots by an experimental adaptation of training simulator components. A mounted camera system continuously monitors the relative position and orientation of the welding torch and workpiece. The simulation contains images of metal textures and a welding seam that are computed in real-time and that are displayed using augmented reality technology. Feedback on deviations from the ideal position, orientation, and movement is displayed during the process and can also be analysed afterwards. The experimental application is strongly limited by the restriction to a given set of basic workpieces. However, the visual feedback was considered by the programmers to be very helpful and the application showed great potential that could be used for dedicated industrial products.
\end{abstract}

\section{Introduction}

Automatisation technology within the automotive sector strongly relies on welding robots [1]. Due to the ongoing trend towards a 'digital factory', this is not expected to change within the foreseeable future [2], [3].
The setup of the welding robots is usually performed by a qualified programmer in multiple iterations. The body parts that are used during setup are usually scrapped. Nowadays, the welding programmes are often prepared in CAD environments or during other forms of simulations, but this still does not lead to acceptable quality levels without conventional testing. As current car models inherit up to 600 complex welding seams, this results in considerable costs.

The presented work focuses on the experimental adaptation of a welding simulator, which is usually used within manual welding training exercises, to guide the programming of welding robots. This simulator visually tracks the relative positions and orientations of welding gear and workpiece to continuously provide feedback to the user. This paper investigates the application of the generated feedback information to guide the teach-in process of welding robots.

\section{State of the Technology}

\subsection{Programming of welding robots}

The most prevalent methods for the programming of welding robots include the generation of programmes based on CAD models, where the path is defined within a CAD environment [4], and the programming by demonstration technique. The latter is commonly used within the automotive sector [5]. During such teach-in processes, the robots are manually guided along their desired path. This path is saved as a program that can later be accessed to perform the teached tasks within the production line. 
In industrial practice, the programming is usually applied by dedicated programmers with limited welding experience. However, some complex welding seams require careful tuning of the welding parameters [6]. This results in one of the major causes for delays during the startup of new production lines.

A similar approach to the presented method has been proposed by $\mathrm{Ni}$ et al. (2017). It generates 3D models of scanned workpieces and employs a haptic input device to define the welding path. The programming is supported by an AR interface as well as haptic force feedback. This approach is designed for scenarios in which the users do not have physical in which the users do not have physical access to the workpieces and the feedback is limited to the positioning of the welding seam, not the generated quality [7].

\subsection{Training simulators for manual welding}

The current key technologies in welding simulations are Virtual Reality and Augmented Reality. During the past decade these technologies were applied to create welding simulators and made the transition towards practical application [8], [9].

These simulators rely on optic measurement to capture the position and movement of a welding torch or electrode [10]. The measured characteristics include stick out, work angle, travel angle, travel path, and travel speed. The available welding simulators differ greatly in physical and functional fidelity, as well as in price.

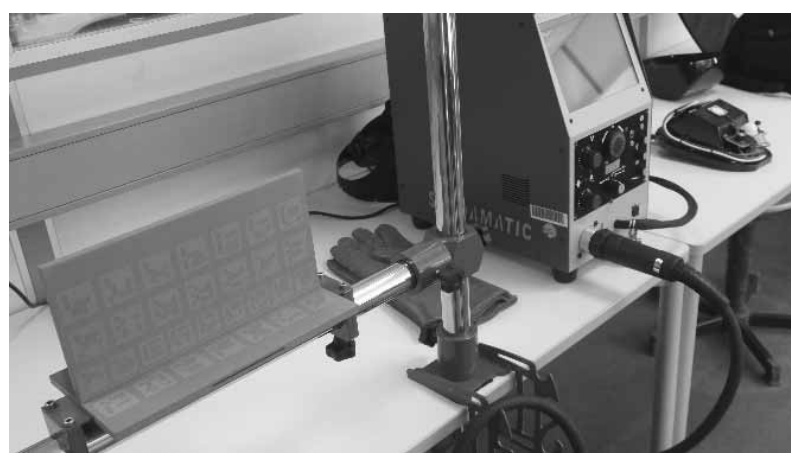

Figure 1. Soldamatic welding simulator.

The applied simulator system is the Soldamatic training simulator for welders (Figure 1), which focusses on manual welding processes and is a commercial product sold by Seabery Soluciones. SL [11]. The hardware consists of a computing unit that is embedded in a welding equipment casing; a welder's helmet that holds cameras, speakers and an integrated display; attachable hand-held devices for MIG/MAG, electrodes, and
GTAW welding processes; a stand; and multiple standard work pieces that are made out of plastic and are printed with reference markers [11], [12].

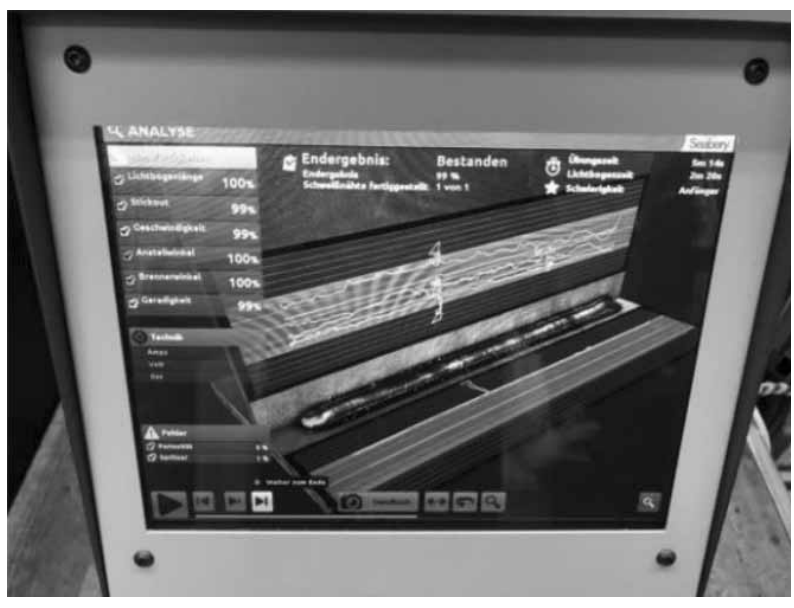

Figure 2. Soldamatic evaluation screen.

A mounted camera system continuously monitors the relative position and orientation of the welding torch and workpiece. The simulation contains images of metal textures and a welding seam that are computed in realtime and that are displayed using augmented reality technology. Feedback on deviations from the ideal position, orientation, and movement is displayed during the process and can also be analysed afterwards (Figure 2).

\section{Methodology}

The paper describes an attempt to provide an assistance during the teach-in process by experimental adaptation of training simulator components. The experiment uses the MIG/MAG simulation in combination with a T-joint workpiece.

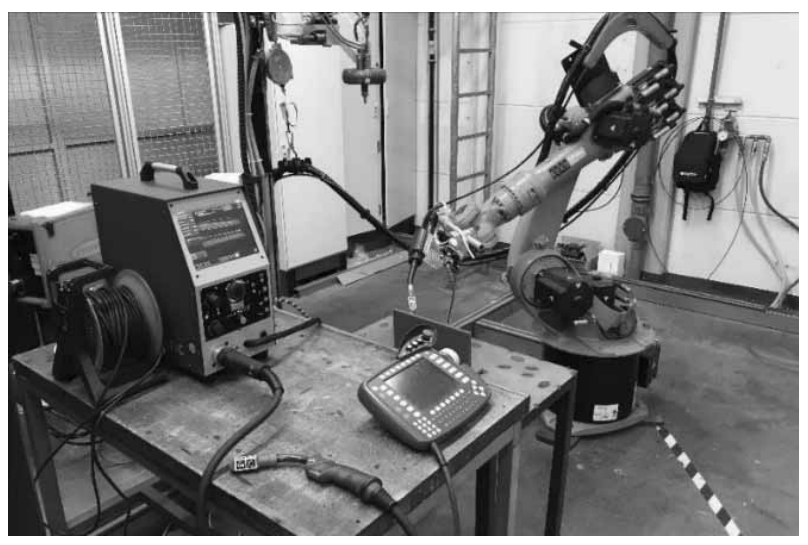

Figure 3. Experimental setup. 
The main components are the Soldamatic welding simulator as well as a KUKA KR15 industrial robot with six axes and a payload of $15 \mathrm{~kg}$. The complete assembly is depicted in Figure 3. The welding helmet of the simulator has been disassembled, as only the camera system was required. Additionally, a light attachment has been constructed to mount the camera system on the industrial robot (Figure 4). The artificial welding gun for the robot has been created with a $3 \mathrm{D}$ printer to resemble the simulator's MIG/MAG gun, as it is required to hold the reference markers in their original position.

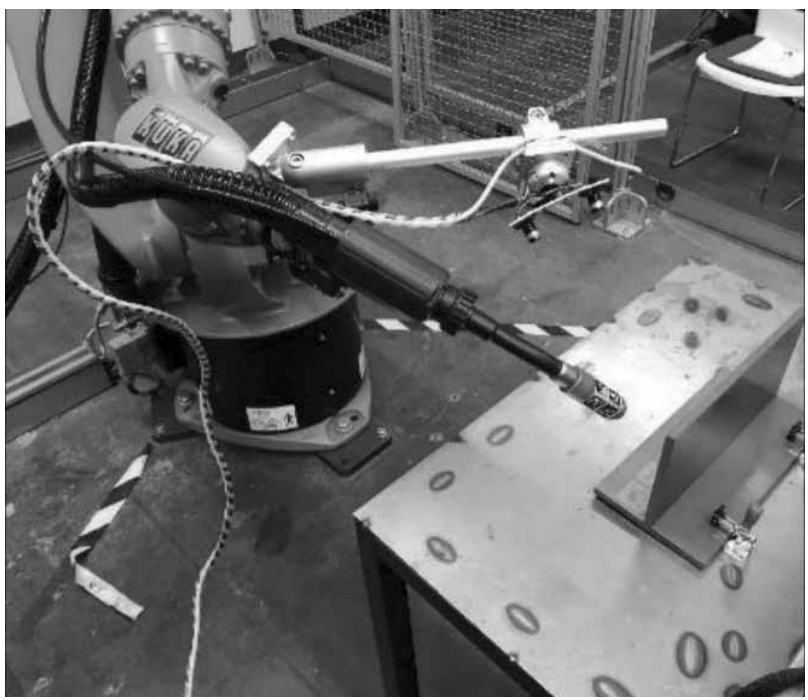

Figure 4. Camera mount and custom welding torch in position over the workpiece.

The simulation parameters are listed in Table 1.

\begin{tabular}{ll}
\hline parameter & value \\
\hline difficulty & beginner \\
\hline material & steel \\
\hline workpiece thickness & $10 \mathrm{~mm}$ \\
\hline welding additive diameter & $1 \mathrm{~mm}$ \\
\hline seam type & single-layer fillet weld \\
\hline protective gas & argon mixed gas \\
\hline current & $23 \mathrm{~A}$ \\
\hline voltage & $30 \mathrm{~V}$ \\
\hline
\end{tabular}

Table 1. Selected simulation parameters.

The experiment has been run in a configuration for beginners, as this offers the most guidance during the process. The simulations' feedback has been applied to tune the position, orientation, and movement of the welding robot.
The robot has been programmed with an average speed of $1,5 \mathrm{~mm} / \mathrm{s}$ and five reference points have been defined along the weld. Once the calibration has been optimized according to the simulation, the exercise was performed multiple times.

The final evaluation has been performed by industrial experts, who included welding trainees, welding trainers, and maintenance staff.

\section{Findings and Limitations}

Once the programming of the welding robot had been tuned according to the feedback of the simulation, the repetition of the experiment constantly led to positive results, which indicates a certain degree of consistency.

The industrial experts stated the application could be used to display and correct position and orientation of the welding torch relative to the workpiece. The ideal configuration of these parameters was considered to be similar to the programming made based on the simulation. However, the velocity that is demanded by the simulation, is estimated to be too low for industrial practice and may ultimately lead to the destruction of the workpiece due to burning through.

The practical usability of the simulations in production was rated as high by the maintenance employee. Even trained welding experts benefit in his opinion from the guidance, since the programming of a welding robot, in contrast to manual welding, cannot be performed intuitively. The technology also provides the opportunity to have an initial teach-in done by a robot expert, so that a welding expert is only required to assist at the end of the teach-in process for additional fine-tuning operations.

It was also highlighted that the working position of the programmer and his vision on the task are improved by the simulation. Only in rare moments, a detailed look at the exact position of the nozzle must be taken. The adjustment of angle and distance can be done on the monitor of the simulation device. This could be particularly helpful in the case of inaccessible or unergonomic seam positions.

Overall, the experts were sceptical as to whether the simulation device can reproduce the very complex processes involved in industrial welds. Necessary changes in the speed with varying wall thicknesses, material changes or elaborate curves are initially not provided in the system. 


\section{Conclusion and Outlook}

The experimental application of the training simulator towards the teach-in of welding robots has been performed for a sample T-joint workpiece. The industrial experts reported the feedback through Augmented Reality a considerable benefit in finding the correct position and orientation of the welding torch. This benefit would be especially relevant in settings with limited access or visibility.

However, the experimental application is strongly limited by restriction to a given set of basic workpieces. The introduction of additional workpieces to the Soldamatic simulation has already been performed in few cases but requires considerable effort and interaction with the developer. The approach described by Ni et al. (2017) employs a scanning module that creates point clouds of the workpiece [7] and could be a possible approach to overcome this barrier. A method to define the seam positions would be required as well, which should be flexible enough to follow the outline of complex seams and allow for changes in material thickness.

Additional challenges were imposed by the optical sensors, which had to be positioned at an average distance of $300 \mathrm{~mm}$ to the workpiece. The recognition was impeded by vibrations of the system that were caused by robot movement. A dedicated application should be designed rather compact to allow for welds that are difficult to access.

\section{Acknowledgement}

The authors would like to thank the Mercedes-Benz plant in Bremen as well as the Daimler Zukunftswerkstatt for the opportunity and support necessary to realize the experiments, as well as the German Federal Ministry of Education and Research (BMBF) for their support in the project 'MESA - Media Use in Welding Education' (grant number 01PD14016).

\section{References}

[1] Bauernhansl T, Ten Hompel M, Vogel-Heuser B. Industrie 4.0 in Produktion, Automatisierung und Logistik: Anwendung, Technologien und Migration. Wiesbaden: Springer, Vieweg; 2014.

[2] Hömberg D, Landry C, Skutella M, Welz WA. Automatic Reconfiguration of Robotic Welding Cells. Mathindustry 2017; 27: 183-203.

[3] Lüder A, Schmidt N. Challenges of Mechatronical Engineering of Production Systems: An Automation System Engineering View. Mathindustry 2017; 27: 93-114.

[4] Ferreira LA, Figueira YL, Iglesias IF, Souto MÁ. Offline CAD-based Robot Programming and Welding Parametrization of a Flexible and Adaptive Robotic Cell Using Enriched CAD/CAM System for Shipbuilding. Procedia Manufacturing 2017; 11: 215-223.

[5] Kah P, Shrestha M, Hiltunen E, Martikainen J. Robotic arc welding sensors and programming in industrial applications. International Journal of Mechanical and Materials Engineering 2015; 10(13).

[6] Horváth CM, Korondi P, Thomessen T. Robotized multipass Tungsten Inner Gas welding of Francis hydro power turbines. Proceedings of the 26th International Symposium on Industrial Electronics (ISIE); 2017; 1759-1765.

[7] Ni D, Yew AWW, Ong SK, Nee AYC, Haptic and visual augmented reality interface for programming welding robots. Advances in Manufacturing 2017; 5(3): 191-198.

[8] Fast K, Gifford T, Yancey R. Virtual training for welding. Proceedings of the 3rd IEEE and ACM International Symposium on Mixed and Augmented Reality (ISMAR 2004); 2004; Arlington; 298-299.

[9] White S, Prachyabrued M, Baghi D, Aglawe A, Reiners D, Borst C, Chambers T. Virtual welder trainer. Proceedings of the IEEE Virtual Reality Conference 2009; 2009; Lafayette; 303-303.

[10] Okimoto MLL, Okimoto PC, Goldbach CE. User experience in augmented reality applied to the welding education. Procedia Manufacturing; 2015; 3: 6223-6227.

[11] Knoke B, Thoben KD. Integration of Simulation-based Training for Welders. Simulation Notes Europe 2017; 27(1): 37-44.

[12] Seabery Soluciones. Soldamatic educational augmented reality: la tecnología educativa más avanzada y competitiva para la formación de soldadores, $100 \%$ española. Soldadura y tecnologías de union 2012; 23(130): 58-60. 